\author{
RESEARCHPAPER
}

\title{
Phytochemical screening of Ocimum sanctum (Tulsi), Azadirachta indica (Neem) and Phyllanthus emblica (Amla)
}

\author{
ANJALI TIWARI, ANKIT PANDEY AND O.P. VERMA
}

Department of Molecular and Cellular Engineering, Jacob School of Biotechnology and Bio-Engineering, Sam Higginbottom Institute of Agriculture, Technology and Sciences, ALLAHABAD (U.P.) INDIA

Email : om.verma@shiats.edu.in

Article Info :Received : 27.11.2015; Revised : 07.01.2016; Accepted : 06.02.2016

The use of plant based drugs and chemicals for curing various ailments and personal adornment is as old as human civilization. Plants and plant-based medicaments are the basis of many of the modern pharmaceuticals we use today for our various ailments. Methanolic extracts of dried leaves of Ocimum sanctum, Azadirachta indica and Phyllanthus emblica were used for the comparative study of phytochemical constituents. A qualitative phytochemical analysis was performed for the detection of alkaloids, glycosides, saponins, steroids, flavonoids, tannins and reducing sugar. The highest yield of methanolic extract was found in Azadirachta indica (29.08\%). Ocimum sanctum contained all the chemicals except flavonoids and reducing sugar, however, the Colquhounia coccinea lacked alkaloids and reducing sugar.

Key words : Phytochemical screening, Alkaloids, Glycosides, Steroids, Flavonoids, Tannins, Reducing sugar

How to cite this paper : Tiwari, Anjali, Pandey, Ankit and Verma, O.P. (2016). Phytochemical screening of Ocimum sanctum (Tulsi), Azadirachta indica (Neem)and Phyllanthus emblica (Amla). Asian J. Bio. Sci., 11 (1) : 28-31 [Special Issue of AFBSAH-2016]. 